\title{
Biometrical analyses of linolenic acid content of soybean seeds
}

\author{
Abelmon da Silva Gesteira ${ }^{1}$, Ivan Schuster ${ }^{1}$, Inês Chamel José ${ }^{1}$, Newton Deniz Piovesan ${ }^{1}$, \\ José Marcelo Soriano Viana ${ }^{2}$, Everaldo Gonçalves de Barros ${ }^{1,2}$ and Maurilio Alves Moreira ${ }^{1,3}$ \\ ${ }^{1}$ Instituto de Biotecnologia Aplicada à Agropecuária (BIOAGRO), Universidade Federal de Viçosa, \\ Viçosa, MG, Brazil. \\ ${ }^{2}$ Departamento de Biologia Geral, Universidade Federal de Viçosa, Viçosa, MG, Brazil. \\ ${ }^{3}$ Departamento de Bioquímica e Biologia Molecular, Universidade Federal de Viçosa, Viçosa, MG, Brazil.
}

\begin{abstract}
The genetic reduction of linolenic acid levels increases the quality and stability of soybean oil. The objective of this study was to determine the inheritance and evaluate the nature and magnitude of gene effects on soybean seed linolenic acid level. Means and variances of $F_{1}, F_{2}$, and $F_{3}$ generations were made from the cross between accession BARC-12 (low linolenic acid content) and the commercial Brazilian cultivar CAC-1 (normal linolenic acid content). The results demonstrated that linolenic acid content in soybean is under the genetic control of a small number of genes. The additive model explained the means for the three generations and for the parents. Non-allelic gene interactions had little effect on the determination of genotypic values for the individuals. The generation means and population variation analyses demonstrated that the dominance deviations contribute little to the trait. These results showed that backcross breeding programs can be used to introduce the low linolenic acid content trait into soybean seeds, since it is possible to identify with very high accuracy the desired genotypes in segregating populations.
\end{abstract}

Key words: soybean oil composition, linolenic acid content, biometrical analyses.

Received: November 20, 2000; accepted: November 21, 2002.

\section{Introduction}

Soybean oil is considered to be of low processing cost. However, for soybean oil to become more competitive, some nutritional and functional traits must be genetically improved compared to other edible oils (Yadav, 1996). The functional and nutritional value of vegetable oils can be dictated by their fatty acid composition. Linolenic acid, with three double bonds, is extremely susceptible to oxidation. According to Neff et al. (1992), there is a positive correlation $(\mathrm{r}=0.81)$ between the rate of peroxide formation and the number of double bonds present in the fatty acid molecule. There is also a negative correlation $(\mathrm{r}=-0.89)$ between linolenic acid content and oil flavor (Liu and White, 1992). Therefore, hydrogenation of soybean oil has been used to chemically reduce the level of linolenic acid to about $2 \%$ in order to increase oil oxidative stability. Nevertheless, the chemical process is costly and the selective hydrogenation of linoleic and linolenic acids is not totally under control (Yadav, 1996). The reduction of linolenic acid content via breeding is the most effective

Send correspondence to Maurilio Alves Moreira. Instituto de Biotecnologia Aplicada à Agropecuária (BIOAGRO), Universidade Federal de Viçosa, 36571-000 Viçosa, MG, Brazil. E-mail: moreira@ ufv.br. way to improve soybean oil quality. Inheritance studies and genetic parameter estimation are extremely valuable for establishing breeding strategies to alter fatty acid content in soybean oil.

BARC-12 is a low linolenic acid (3\%) line obtained by Leffel (1994) by crossing and selecting the two full-sib lines N85-2176 and N85-2124. These two lines were selected by Burton et al. (1989) in the cross N78-2245 with PI 123440 , both with low linolenic acid content. BARC-12 displays significantly lower linolenic acid compared to its progenitors (N85-2176 and N85-2124) and lines A5, C1640, and N85-2131, which also have low linolenic acid contents.

Heritability is considered to be one of the most important genetic parameters of the population under selection. Narrow sense heritability expresses the proportion of the total variance that can be attributed to the average gene effects. An important function of the heritability parameter is its predictive role, expressing the degree of correspondence between the phenotypic and genotypic values (Falconer and Mackay, 1997). Heritability is not restricted to the trait itself but is also related to the population and environmental conditions to which the plants have been submitted (Falconer and Mackay, 1997). 
The objectives of this work were to analyse the inheritance of linolenic acid content and to evaluate the nature and magnitude of the gene effects which control this trait in soybean seeds.

\section{Material and Methods}

\section{Genetic material and crosses}

Accession BARC-12, with less than 30 g. $\mathrm{kg}^{-1}$ of linolenic acid in the oil fraction, was developed by USDAARS in Beltsville, MD, USA (Leffel, 1994). This accession was crossed with the Brazilian commercial cultivar CAC-1, which presents an average of $85 \mathrm{~g} . \mathrm{kg}^{-1}$ of linolenic acid in the oil fraction. Crosses were made in the greenhouse during the summer of 1995 . Hybrid seeds, confirmed by fatty acid composition, were sown in two-liter pots and two plants/pot were cultivated. The $F_{1}$ plant that produced the highest number of seeds was used to generate the $F_{2}$ population. A total of $357 \mathrm{~F}_{2}$ seeds from a single $\mathrm{F}_{1}$ plant were harvested in December 1995, and numbered individually for the non-destructive single seed fatty acid composition analysis. $F_{2}$ and parental seeds were sown directly into two-liter pots by using three seeds per pot. Plants were grown in the greenhouse under natural photoperiod, at $25 \pm 5{ }^{\circ} \mathrm{C}$, during the winter of 1996 . The linolenic acid content was also analyzed in 10 seeds of $45 \mathrm{~F}_{3}$ random families. $F_{3}$ families and parents were grown in the greenhouse under the same conditions described for F2 generation, during the summer of 1997.

\section{Determination of fatty acid composition}

The fatty acid composition of soybean oil was determined by gas chromatography-single seed analysis. A 30-mg portion was cut into small pieces with a razor blade, from the opposite side of the seed embryo, and macerated. The sample was divided into two 15 -mg portions and one milliliter of hexane was added to each these portions. The mixture was incubated at $4{ }^{\circ} \mathrm{C}$ for $16 \mathrm{~h}$ under $\mathrm{N}_{2}$ atmosphere. After this period, the hexane extract was poured into another test tube and the solvent was evaporated by $\mathrm{N}_{2}$ injection. The fatty acid methyl esters were prepared by a methodology described by Bubeck et al. (1989). A volume of $0.4 \mathrm{~mL}$ of $1 \mathrm{M}$ sodium methoxide was added to the lipid fraction and the test tubes were placed in a water bath at $30{ }^{\circ} \mathrm{C}$ for $1 \mathrm{~h}$. One $\mathrm{mL}$ of water and $1 \mathrm{~mL}$ of hexane were then added to the test tubes. After one hour, $0.75 \mathrm{~mL}$ of the organic phase was transferred to another test tube containing anhydrous sodium sulfate. Finally, $1 \mu \mathrm{L}$ of the organic phase was injected into a SHIMADZU GC-17A gas chromatograph, equipped with an AOC-17 auto-injector and a C-R7A integrator. A carbowax column $(30 \mathrm{~m} \mathrm{x}$ $0.32 \mathrm{~mm}$ ) was used and the analytical conditions were as follows: temperatures of the column, injector, and detector were 225,245 , and $280^{\circ} \mathrm{C}$, respectively; Nitrogen gas flow rate, $1.3 \mathrm{~mL} \cdot \mathrm{min}^{-1}$.

\section{Generation mean analysis}

The genetic components of the means were estimated by fitting the model $\mathrm{Y}=\mathrm{X} \beta+\varepsilon$, where $\mathrm{Y}$ is the mean vector for the generations, $X$, the coefficient matrix, $\beta$, the genetic parameters vector to be estimated, and $\varepsilon$, the mean-associated residual vector. The estimation was based on the weighted least square method (Mather and Jinks, 1971).

The null hypothesis for each parameter was evaluated by the $t$ test. The number of degrees of freedom used was given by adding the degrees of freedom from each generation that constituted the estimator expression. The variance of each effect was obtained by applying the variance properties to the estimator of each genetic parameter assuming that generation means are independent (Mather and Jinks, 1971).

For variance analysis, the error vector was considered to be a multidimensional normal distribution with null expectation and covariance matrix equal to $\mathrm{D}$, being $\mathrm{D}$ a diagonal matrix. The diagonal elements of $\mathrm{D}$ are the inverse of the variances of the generation means.

\section{Variances analyses}

The components of the genotypic variance $\left(\sigma_{\mathrm{G}}^{2}\right)$ in the base population $\left(\mathrm{F}_{2}\right)$ were estimated by using the phenotypic variances $\left(\sigma_{\mathrm{P}}^{2}\right)$ of BARC-12 (P2) and CAC-1 (P1) and of the $\mathrm{F}_{1}, \mathrm{~F}_{2}$, and $\mathrm{F}_{3}$ generations. Considering the additive model, the genotypic variance contains the additive genetic variance $\left(\sigma_{\mathrm{A}}^{2}\right)$ and the variance due to the dominance $\left(\sigma_{\mathrm{D}}^{2}\right)$.

The broad and narrow sense heritabilities were determined by the expressions $\mathrm{h}_{\mathrm{b}}^{2}=\hat{\sigma}_{\mathrm{Gsu}} / \hat{\sigma}_{\mathrm{Psu}}^{2}$ and $\mathrm{h}_{\mathrm{n}}^{2}=\hat{\sigma}_{\mathrm{Gsu}}^{2} / \hat{\sigma}_{\mathrm{Psu}}^{2}$, where the parameters $\sigma_{\mathrm{Gsu}}^{2}, \sigma_{\mathrm{Psu}}^{2} \mathrm{e} \sigma_{\mathrm{Asu}}^{2}$ are the genotypic, phenotypic, and additive variances, respectively, among the selection units. Since the $F_{2}$ and $F_{3}$ generations were not analyzed at the same time, the parents were analyzed in each generation and their phenotypic variances were used as estimators of environmental variance for the $\mathrm{F}_{2}$ and $\mathrm{F}_{3}$ generations.

\section{Results and Discussion}

\section{Inheritance and heritability}

The means and variances of the linolenic acid content in the five generations evaluated are shown in Table 1. The results from the $\mathrm{F}_{2}$ and $\mathrm{F}_{3}$ resulted in a null estimate of $\sigma_{\mathrm{D}}^{2}$ (Table 2). For this reason, heritability in the narrow sense was assumed to be equal to heritability in the broad sense. Based on these results, we concluded that approximately $75 \%$ of the total variation in the $\mathrm{F}_{2}$ population could be attributed to genetic effects of additive nature. These data suggest the viability of using simple breeding methods for genetic improvement of the low linolenic acid content trait in the soybean seed oil fraction. 
Table 1 - Means and variances of CAC-1, BARC-12, and three generations derived from these parents for linolenic acid content.

\begin{tabular}{lccc}
\hline Generation & Number of seeds & Mean & Variance \\
\hline CAC-1 & 20 & 9.5062 & 0.6711 \\
BARC-12 & 22 & 3.7455 & 0.1086 \\
$\mathrm{~F}_{1}$ & 5 & 5.4007 & 0.4662 \\
$\mathrm{~F}_{2}$ & 357 & 5.7555 & 1.7032 \\
$\mathrm{~F}_{3}$ & $450^{*}$ & 6.8773 & 3.8261 \\
\hline
\end{tabular}

*Total of 45 families, 10 seeds of each.

Table 2 - Estimates of the phenotypic, genotypic, environmental, and additive variances and heritabilities for linolenic acid content in the $\mathrm{F}_{2}$ and $\mathrm{F}_{3}$ generation of soybean crosses between CAC-1 and BARC-12.

\begin{tabular}{lcccc}
\hline Parameters & $\mathrm{F}_{2}$ & \multicolumn{2}{c}{$\mathrm{F}_{3}$} \\
\cline { 3 - 4 } & & Within families & Between families & Total \\
\hline$\sigma_{\mathrm{p}}^{2}$ & 1.7032 & 2.4085 & 1.4176 & 3.8261 \\
$\sigma_{\mathrm{e}}^{2}$ & 0.4280 & 0.3852 & 0.0428 & 0.4280 \\
$\sigma_{\mathrm{g}}^{2}$ & 1.2751 & 2.3657 & 1.0324 & 3.3980 \\
$\sigma_{\mathrm{A}}^{2 \#}$ & 1.2751 & 4.7139 & 1.0324 & 2.2654 \\
$\mathrm{~h}_{\mathrm{a}}^{2}=\mathrm{h}_{\mathrm{r}}^{2} \cdot$ & 0.7486 & 0.9822 & 0.7282 & 0.8881 \\
\hline
\end{tabular}

\#Additve variance evaluated for each generation.

-Since variance due to dominance deviations is null and broad and narrow sense heritabilities are equal.

The coefficient of symmetry for the $\mathrm{F}_{2}$ population did not differ significantly from zero (Table 3 ). Since dominance effects tend to deviate $\mathrm{F}_{2}$ means towards the progenitor bearing the highest concentration of dominant genes, these observations confirmed that deviations due to dominance were of small magnitude and were not significant.

The linolenic acid content showed high heritability, which is in agreement with the results obtained by Fehr et al. (1992). As a general rule, traits defined by a small number of genes show high heritabilities in early generations, permitting the fixation of distinct genotypes by using a small number of selfing generations (Anand and Torrie, 1963). Heritabilities between and within $F_{3}$ families indicated that gains to be achieved by mass selection should be

Table 3 - Mean, maximum and minimum values, standard deviation and coefficient of symmetry of linolenic acid content of soybean seeds in the $\mathrm{F}_{2}$ population.

\begin{tabular}{lc}
\hline Statistics & Estimate \\
\hline Number of individuals & 357 \\
Mean & 5.7555 \\
Minimum & 3.1293 \\
Maximum & 9.2773 \\
Standard deviation & 1.3051 \\
Symmetry & $0.2271^{\mathrm{ns}}$ \\
\hline
\end{tabular}

${ }^{\mathrm{ns}}$ not significantly different from zero $(\mathrm{p}<0.01)$.
Table 4 - Estimates for mean (m) and additive (d) parameters obtained from the means and significance test for the null hypothesis of these parameters in soybean populations.

\begin{tabular}{lcccc}
\hline Parameters & Estimate & $\mathrm{t}$ & $\mathrm{DF}$ & Significance \\
\hline $\mathrm{m}$ & 6.2518 & & & \\
$\mathrm{~d}$ & 2.6018 & 5.54 & 3 & $\mathrm{p}<0.01$ \\
\hline
\end{tabular}

m - mean; $\mathrm{d}$ - additive.

higher than those obtained by family selection. Although this is not the theoretically expected result, we suggest that either mass or family selection is efficient for promoting gains. This evidence is important for breeding programs because, associated with the high heritability, it suggests that it is possible to select desirable genotypes in the $F_{2}$ population. Furthermore, the data point out that simple breeding methods such as mass selection or backrossing can be used to produce low linolenic acid content cultivars.

Estimates of the components of the additive model as well as the significance tests are shown in Table 4. The number of associated degrees of freedom corresponds to the sum of the degrees of freedom of each generation used in the estimation of the parameter.

The results obtained in the means and variance analyses showed absence of dominance (Table 4). Based on these results we concluded that an additive model is sufficient to explain practically all variation in linolenic acid content in soybean. The absence of an epistatic effect, evidenced by variance analysis, associated with an absence of dominance, evidenced by means analyses as well as variance analyses, demonstrated that will be easy to obtain pure lines with low linolenic acid content.

The broad sense heritability in the $\mathrm{F}_{2}$ generation and that based on $\mathrm{F}_{3}$ individuals demonstrated that successeful selection can be achieved without any need for breeding methods based on progeny tests. Either stratified mass selection or the backcross method are efficient for selecting low linolenic acid trait, since selection is not influenced by dominance deviations and this trait presents high narrow sense heritability. As evidenced by heritabilities between and within $\mathrm{F}_{3}$ families, it is easier to obtain gains via selection based on individuals than selection based on families. The introgression of the low linolenic acid content trait in elite soybean cultivars can be achieved rapidly since such a trait is easily selected in early generations and the backcross method can be used to recover the elite cultivars.

\section{Acknowledgments}

This study was supported by a grant from FAPEMIG to M.A. Moreira. A.S. Gesteira was recipient of MS scholarship from CNPq. 


\section{References}

Anand SC and Torrie JH (1963) Heritability of yield and other traits interrelationships among traits in $\mathrm{F}_{3}$ and $\mathrm{F}_{4}$ generations of three soybeans crosses. Crop Sci 3:508-511.

Bubeck DM, Fehr WR and Hammond EG (1989) Inheritance of palmitic and stearic acid mutants of soybean. Crop Sci 29:652-656.

Burton JW, Wilson RF, Brim CA and Rinne RW (1989) Registration of soybean germoplasm lines with modified fatty acid composition of seed oil. Crop Sci 29:1583.

Burton GW (1951) Quantitative inheritance in pearl millet (Pennisetum glaucum). Agron J Madison 51:42-46.

Falconer DS and Mackay TFC (1997) Introduction to quantitative genetics. Fourth Edition, Longman, Edinburgh, 464 pp.

Fehr WR, Welke GA, Hammond EG, Duvick DN and Cianzio SR (1992) Inheritance of reduced linolenic acid content in soybean genotypes A16 and A17. Crop Sci 32:903-906.
Leffel RC (1994) Registration of BARC-12 a low linolenic acid soybean germplasm line. Crop Sci 34:1426-1427.

Liu HR and White PJ (1992) Oxidative stability of soybean oil with altered fatty acid compositions. J Am Oil Chem Soc 69:528-532.

Mather K and Jinks JL (1971) Biometrical Genetics: The study of continuous variation. New York: Cornell University Press, $382 \mathrm{pp}$.

Neff WE, Selke E, Mounts TL, Rinsch W, Frankel EN and Zeitoun MAM (1992) Effect of triacylglycerol composition and structures on oxidative germoplasm. J Am Oil Chem Soc 69:111-118.

Yadav NS (1996) Genetic modification of soybean oil quality. In: Verma DPS and Shoemaker RC (eds) Soybean genetics, molecular biology and biotechnology. USA: CAB INTERNATIONAL, pp 165-188.

Zar JH (1996) Biostatistical analysis. Upper Saddle River, New Jersey. Prentice Hall. Third Edition, 662 pp.

Associate Editor: Natal Antonio Vello 